Research Article

\title{
Analisis Tingkat Efisiensi pada Sistem Pengkondisian Udara di Gedung Auditorium
} Universitas Muhammadiyah Pontianak

Riski Nurhalim ${ }^{1}$, Gunarto ${ }^{2}$, Eko Sarwono ${ }^{3}$, Fuazen $^{4}$

Teknik Mesin, Fakultas Teknik, Universitas Muhammadiyah Pontianak, Indonesia

Email:Nurhalimriski97@gmail.com,Gunarto@gmail.com,Ekosarwono@gmail.com,Fauzen@gmail.com

Corespondensi author : Nurhalimriski97@gmail.com

\section{Article History:}

Online first:

18 January 2021

Keywords: Cooling Load, Power, $A C$

Kata Kunci: Beban

Pendingin, Daya

Pendingin, AC
ABSTRACT

Observing various events such as the angle of sunlight, measuring the temperature of the outer wall, various accessories available and the types of activities carried out. Then do the calculations with CLTD (Cooling Load Temperature Difference) method based on ASHRAE 1997. The results obtained are cooling loads from such as brick walls with plaster layers, glass, aluminum alloy roofs, concrete and ceramic floors, lamps, occupants, electronic equipment. and 1,500 maximum number of people in the Pontianak Muhammadiyah Auditorium Building was 349.772,358 Watt or 132,60 PK. The current installed air conditioner has a capacity of 40 PK, so it needs 92,6 PK PK more or 19 units of cooling equipment, each of which has a capacity of $5 \mathrm{PK}$ so that cooling in the room is more efficient.

\section{ABSTRAK}

Mengamati berbagai kejadian seperti sudut pancaran sinar matahari langsung, mengukur dimensi ruangan, berbagai aksesoris yang ada dan jenis kegiatan yang dilakukan. Kemudian melakukan perhitungan dengan metode CLTD (Cooling Load Temperature Difference) berdasarkan ASHRAE 1997. Hasil penelitian yang didapat yaitu beban pendingin dari seperti dinding bata dengan lapisan plaster, kaca, atap dari perpaduan aluminium, lantai dari beton dan keramik, lampu, penghuni, peralatan elektronik dan 1.500 orang jumlah maksimal pada ruangan Auditorium Universitas Muhammadiyah Pontianak didapat sebesar 349.772,358 Watt atau 132,60 PK. AC Standing Floor 8 unit, 1 unit berkapasitas 5 PK yang terpasang saat ini berkapasitas $40 \mathrm{PK}$, maka dibutuhkan 92,6 PK lagi atau 19 unit alat pendingin yang masing-masing alat berkapasitas 5 PK agar pendinginan diruangan tersebut lebih efisien. 


\section{PENDAHULUAN}

Indonesia sebagai negara yang beriklim tropis, mempunyai kondisi udara dengan temperatur dan kelembaban yang cukup tinggi. Keadaan kondisi udara ini dirasakan kurang nyaman, sehingga diperlukan suatu alat yang dapat mengubah kondisi udara dari temparatur dan kelembaban yang tinggi menjadi kondisi udara yang bertemperatur dan kelembaban yang rendah, yaitu dengan peralatan pengkondisian udara (Air Conditioning)[1]. Penyegaran udara adalah suatu proses mendinginkan udara sehingga dapat mencapai temperatur dan kelembapan yang sesuai dengan yang dipersyaratkan terhadap kondisi udara dari suatu ruangan tertentu. Selain itu, mengatur aliran udara dan kebersihannya[2]. Refrigerasi adalah suatu usaha untuk mencapai atau memperoleh dan menjaga temperatur lebih rendah dari temperatur atmosfer lingkungan atau sama dengan memindahkan panas dari temperatur rendah ke temperatur yang tinggi dengan melakukan kerja terhadap system[3]. Instalasi tata udara merupakan utilitas gedung atau bangunan yang cukup penting keberadaannya. Kenyamanan merupakan salah satu alasan yang menyebabkan instalasi tata udara perlu dipasang pada bangunan yang akan digunakan sebagai tempat beraktivitas atau bisnis[4]. Bangunan merupakan faktor penyaring penyebab alamiah ketidak nyamanan, seperti hujan, terik matahari, angin kencang, dan udara panas tropis, agar tidak masuk ke dalam bangunan. Udara luar yang panas dimodifikasi bangunan dengan bantuan AC menjadi udara dingin[5].

\section{METODE PENELITIAN}

Metode yang digunakan dalam pengumpulan data pada penelitian ini yaitu "Metode Fungsi Transfer/Handbook Ashrae Fundamental 1997'. Dalam penelitian ini, dilakukan berupa perhitungan beban pendingin dari internal dan eksternal, kemudian akan dilihat hasilnya berapa PK seharusnya untuk mendinginkan Ruangan Auditorium Universitas Muhammadiyah Pontianak di acara wisuda.

Tabel 1. Data Gedung Auditorium

\begin{tabular}{|c|c|}
\hline Parameter & Nilai \\
\hline Panjang dan lebar Audit & $32 \mathrm{~m} \times 32 \mathrm{~m}$ \\
\hline Pintu kayu lantai bawah (4 buah) & $210 \mathrm{~cm} \mathrm{x} \mathrm{79,8} \mathrm{cm}$ \\
\hline Pintu kayu lantai Atas (2 buah) & $211 \mathrm{~cm} \mathrm{x} 79 \mathrm{~cm}$ \\
\hline Jendela kaca atas ( 5 buah) & $76 \mathrm{~cm} \mathrm{x} \mathrm{60,5} \mathrm{cm}$ \\
\hline $\begin{array}{l}\text { Jendela kaca atas bagian kanan } \\
\text { ( } 1 \text { buah) }\end{array}$ & $76 \mathrm{~cm} \mathrm{x} 87,5 \mathrm{~cm}$ \\
\hline Jendela kaca atas bagian kiri (1 buah) & $76 \mathrm{~cm} \mathrm{x} \mathrm{91,5} \mathrm{cm}$ \\
\hline Pintu kaca bawah P x L & $9,831 \mathrm{~m}^{2}$ \\
\hline AC Standing Floor $5 \mathrm{PK}$ terpasang & 8 unit \\
\hline Gedung menghadap arah & Tenggara (SE) \\
\hline Suhu yang dikondisikan & $25,8^{\circ} \mathrm{C}$ \\
\hline $\begin{array}{l}\text { Suhu udara luar kota pontianak bulan } \\
\text { november }\end{array}$ & $36,4^{\circ} \mathrm{C}$ \\
\hline
\end{tabular}




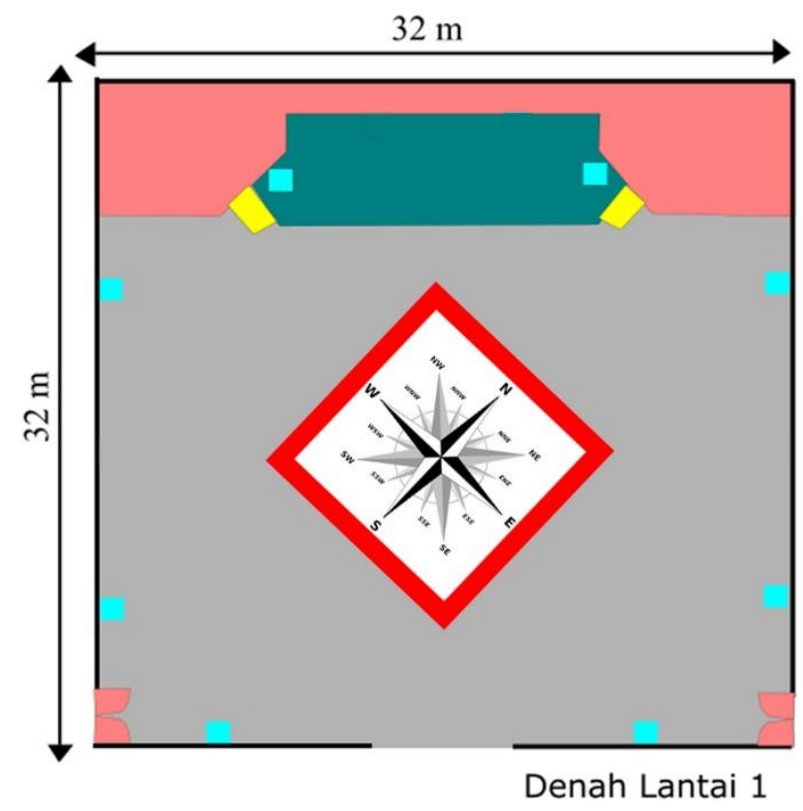

Gambar 1. Instrumen Penelitian

Gedung Auditorium Universitas Muhammadiyah memiliki 2 lantai dengan bangunan menghadap kearah SE (Tenggara). Jam operasional yang digunakan adalah 4 jam kerja, dimulai dari jam 08.00 WIB sampai dengan jam 12.00 WIB, dengan demikian sistem pengkondisian udara juga akan beroperasi selama jam kerja. Dalam perhitungan beban pendingin, perhitungan yang digunakan berdasarkan pada beban puncak. Menurut Saito Heizo dan Wiranto Aris Munandar (1981), kondisi terpanas untuk Indonesia terjadi bulan Mei sampai dengan Oktober. Pada perhitungan beban puncak, khusus untuk kota Pontianak digunakan bulan Agustus biasanya terjadi perubahan musim. Dari musim kemarau menjadi musim penghujan, sehingga suhu udara biasanya akan menjadi lebih panas. Untuk Cooling Load Temperature Differences (CLTD) diambil pada 12.00 WIB, karena pada saat itu gedung menerima sinar matahari yang paling banyak. Berdasarkan standart kenyamanan termal, suhu nyaman optimal antara $22,8-25,8^{\circ} \mathrm{C}$.

\section{HASIL DAN DISKUSI}

Setelah menghitung beban pendinginan, maka dapat diperoleh total beban pendinginan Gedung Auditorium Universitas Muhammadiyah Pontianak, yaitu sebagai berikut : Total Beban = Dinding + Kaca + Atap + Langit-Langit + Lantai + Orang + Lampu + Elektronik + Udara.

Tabel 2. Total Beban Pendingin

\begin{tabular}{clc}
\hline No. & \multicolumn{1}{c}{ Jenis Beban } & Watt \\
\hline 1. & Dinding & 71.649 \\
2. & Kaca & 2.376 \\
3. & Atap & $12.404,30$
\end{tabular}




\section{Langit-Langit}

5. Lantai

6. $\quad$ Orang

7. Lampu

8. Elektronik

9. Udara
$18.778,112$

$52.969,472$

180.375

$6.255,650$

$4.960,2$

4,624

Total $349.772,358$

$1 \mathrm{Watt}=3,412 \mathrm{Btu} / \mathrm{h}$

$349.772,358$ Watt $=132,60 \mathrm{Pk}$

Jadi, untuk kenyamanan thermal di ruangan Auditorium adalah 132,60 Pk dan memerlukan 27 AC Standing Floor.

Denah Peletakan AC Kenyamanan Termal di Lantai 1 dan 2
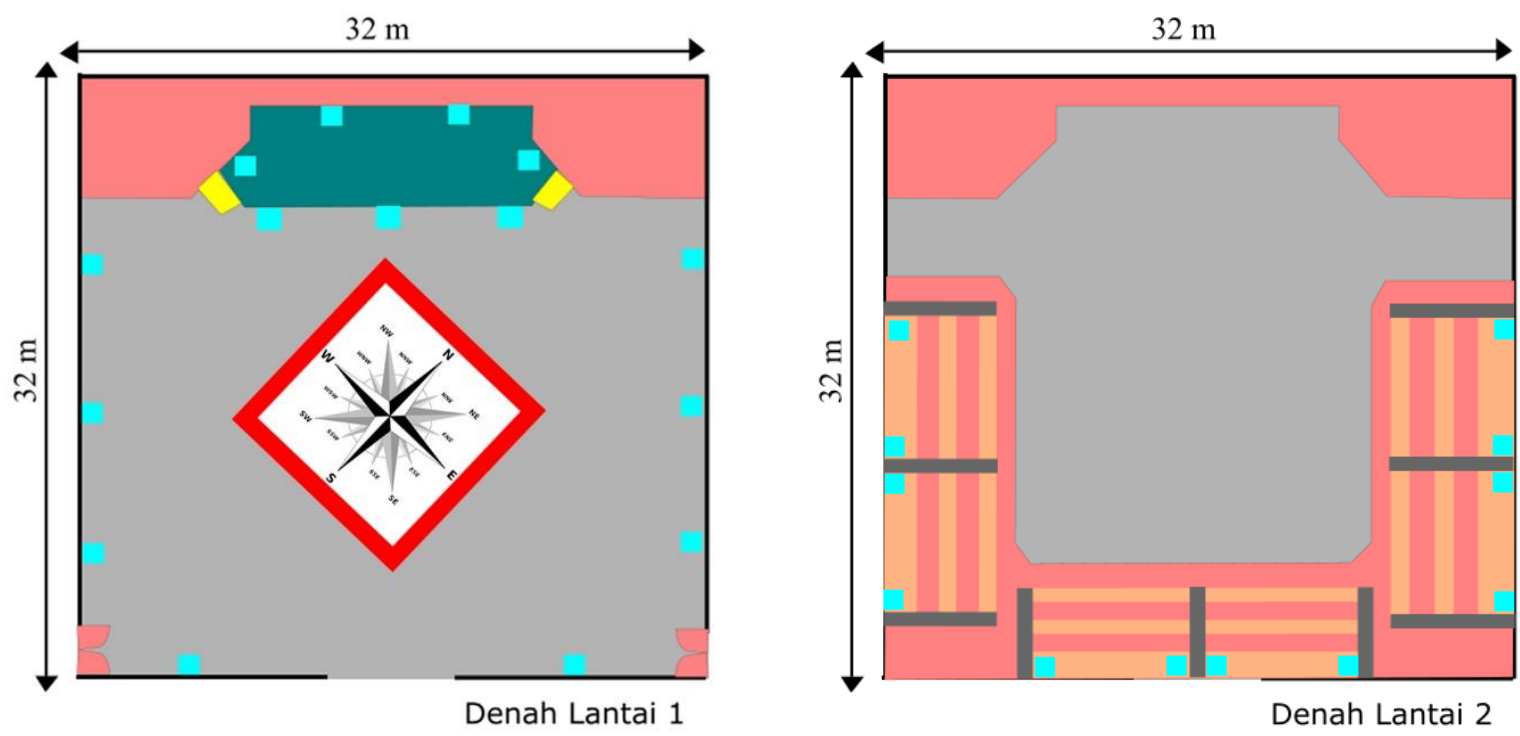

\section{KESIMPULAN}

Mengamati berbagai kejadian seperti sudut pancaran sinar matahari langsung, mengukur dimensi ruangan, berbagai aksesoris yang ada dan jenis kegiatan yang dilakukan. Kemudian melakukan perhitungan dengan metode CLTD (Cooling Load Temperature Difference) berdasarkan ASHRAE 1997. Hasil penelitian yang didapat yaitu beban pendingin dari seperti dinding bata dengan lapisan plaster, kaca, atap dari perpaduan aluminium, lantai dari beton dan keramik, lampu, penghuni, peralatan elektronik dan 1.500 orang jumlah maksimal pada ruangan Auditorium Universitas Muhammadiyah Pontianak didapat sebesar 349.772,358 Watt atau 132,60 PK. AC Standing Floor 8 unit, 1 unit berkapasitas 5 PK yang terpasang saat ini berkapasitas 40 PK, maka dibutuhkan 92,6 PK lagi atau 19 unit alat pendingin yang masingmasing alat berkapasitas $5 \mathrm{PK}$ agar pendinginan diruangan tersebut lebih efisien. 


\section{DAFTAR PUSTAKA}

[1] Mustaqim, Rusnoto, Slamet Subedjo. 2011. Analisa Variasi Beban Pendingin Udara Kapasitas 1 PK pada Ruang Instalasi Uji dengan Pembebanan Lampu. Teknik Mesin. Fakultas Teknik. Universitas Pancasakti Tegal.

[2] Kemas Ridhuan, Andi Rifai. 2013. Analisa Kebutuhan beban Pendingin dan Daya Alat Pendingin AC untuk Aula Kampus 2 UM Metro. Teknik Mesin. Fakultas Teknik. Universitas Muhammadiyah Metro.

[3] Komang Metty Trisna Negara, Hendra Wijaksana, Nengah Suarnadwipa, Made Sucipta. 2010. Analisa Performansi Sistem Pendingin Ruangan dan Efisiensi energi Listrik pada Sistem Water Chiller dengan Penerapan Metode Cooled Energy Storage. Teknik Mesin. Fakultas Teknik. Universitas Udayana.

[4] Andri Setiawan, Joko Prihartono, Purwo Subekti 2014. Perhitungan Beban Pendinginan Instalasi Tata Udara Sistem Fan Coil Chilled Water di Gedung Showroom Mobil Jakarta. Teknik Mesin. Fakultas Teknik. Universitas Pasir Pengaraian.

[5] Rina Dwi Yani. 2017. Analisis Konsumsi Energi Listrik Pada Sistem Pendingin Ruangan (Air Conditioning) Di Gedung Direktorat Politeknik Negeri Pontianak. Teknik Elektro. Fakultas Teknik. Universitas Tanjungpura Pontianak. 